\title{
Canadian Association of Gastroenterology Research Committee Report
}

\author{
Kris Chadee PhD \\ Chair, CAG Research Committee \\ University of Calgary, Calgary, Alberta
}

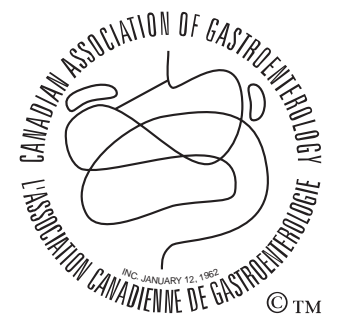

En français voir page 461

$\mathrm{T}$ he goal of the Research Committee is to build, in collaboration with the Canadian Institutes of Health Research (CIHR) and the Canadian Association of Gastroenterology (CAG), Canadian capacity and expertise in the discipline of gastroenterology and nutrition and to promote excellence in research. As chair, I am pleased to update the CAG membership and The Canadian Journal of Gastroenterology readership on the activities of the Research Committee over the past months.

First, I gratefully acknowledge the work done by the entire Research Committee (Table 1). On behalf of the CAG, I would like to thank Drs Nathalie Rivard, Alison Fox-Robichaud and Andre Buret, who completed their term this past February. The assistance of the CAG National Office staff - Mr Paul Sinclair, the CAG National Executive Director; Ms Sandra Daniels, Manager; and Ms Karen Moricz, Administrative Assistant - is also appreciated.

It was another excellent year for investment in gastrointestinal (GI) research in Canada and I am pleased to report that every CAG member, from undergraduate students to professors and clinicians, now has an opportunity to apply for and receive research or training support.

Details relating to eligibility and application processes for all of the following awards are available on the CAG Web site $<$ www.cag-acg.org $>$. The review and assessment of every application complies with CIHR standards and guidelines and any potential conflicts of interest are meticulously identified and avoided.

\section{Operating grants}

The New Investigator Grant, in partnership with Nycomed and the CIHR, was awarded to Amee Manges (PhD, McGill University) for a project titled "The role of altered intestinal microbiota in the etiology of Clostridium difficile-associated disease" and the CAG Operating Grant, in partnership with Abbott and the CIHR, went to Nicola Jones (MD/PhD, University of Toronto) for the project "Helicobacter pylori vacuolating cytotoxin disrupts autophagy".

New for 2007 were the availability of three Endoscopic Research Operating Grants offered in partnership with Olympus and the CIHR. These were awarded to Alan Barkun (MD, McGill University) for the project "The cost-effectiveness

\begin{tabular}{llc}
$\begin{array}{l}\text { Table } 1 \\
\text { Members of the Canadian Association of }\end{array}$ \\
Gastroenterology Research Committee & \\
\hline Member & Institution & Term \\
\hline Chair - Kris Chadee (PhD) & University of Calgary & $2005-2008$ \\
Jan Huizinga (PhD) & McMaster University & $2005-2008$ \\
Karen Madsen (PhD) & University of Alberta & $2005-2008$ \\
Donna-Marie McCafferty & University of Calgary & $2005-2008$ \\
$\begin{array}{l}\text { (PhD) } \\
\text { Paul Moayyedi (MD, PhD) }\end{array}$ & McMaster University & $2005-2008$ \\
Mark Silverberg (MD, PhD) & University of Toronto & $2006-2009$ \\
John Brumell (PhD) & University of Toronto & $2006-2009$ \\
Francois Boudreau (PhD) & University of Sherbrooke & $2007-2010$ \\
Robert Hilsden (MD, PhD) & University of Calgary & $2007-2010$ \\
Thomasz Michalak (MD) & Memorial University & $2007-2010$ \\
Bruce Vallance (PhD) & University of British & $2007-2010$ \\
& Columbia & - \\
Elena Verdu & McMaster University & - \\
(Post-doctoral fellow) & & - \\
Stephen Vanner (MD)* & Queen's University &
\end{tabular}

${ }^{*}$ Representative of Canadian Digestive Health Foundation

of video capsule endoscopy in patients with gastrointestinal bleeding of obscure origin - A randomized clinical trial comparing video capsule endoscopy to push enterscopy", Catherine Dube (MD, University of Calgary) for "Economic evaluation of capsule endoscopy in the evaluation of iron deficiency anemia" and Julia Liu (MD, University of Alberta) for "Understanding endoscopic treatment for gastroesophageal reflux disease".

Seven applications in the New Investigator competition, five applications in the Operating Grant and six applications in the Endoscopic Research Operating Grant competitions were reviewed.

Fellow-to-Faculty Transition Award

No applications for transition awards were received in this year's competition.

The CAG is proud to acknowledge its Benefactor Corporate Sponsors:

\begin{tabular}{|cccc}
\hline $\begin{array}{c}\text { Abbott Laboratories Ltd } \\
\text { Nycomed (formerly ALTANA Pharma) }\end{array}$ & AstraZeneca Canada Inc & Axcan Pharma Inc & Janssen-Ortho Inc \\
Pfizer Canada Inc & Procter \& Gamble Pharmaceuticals & Schering Canada Inc \\
\hline
\end{tabular}




\section{Table 2}

Canadian Association of Gastroenterology-Canadian Institutes of Health Research-Partner Funded Postdoctoral Fellowships (2007)

\begin{tabular}{lllll}
\hline Candidate & Industrial partner & Years & Institution & Supervisor \\
\hline Lorna Friis & AstraZeneca & $2(+1)$ & University of Alberta & D Taylor/M Keelan \\
Bryan Jones & AstraZeneca & $2(+1)$ & University of Calgary & R DeVinney \\
Lisa Elisabeth Månsson & AstraZeneca & $2(+1)$ & University of British Columbia & B Vallance \\
Karen Smith & AstraZeneca & $2(+1)$ & McMaster University & A Macpherson \\
Thomas Walters & AstraZeneca & $2(+1)$ & University of Toronto & A Griffiths/M. Silverberg \\
Sébastian Bergeron & CCFC & 2 & University of Sherbrooke & N Rivard \\
Melanie Gareau & CCFC & 2 & University of Toronto & P Sherman \\
Markus Geuking & CCFC & 2 & McMaster University & A Macpherson \\
Simon Hirota & CCFC & 2 & University of Calgary & P Beck/J MacDonald \\
Woo Yong Lee & CCFC & 2 & University of Calgary & P Kubes \\
Justin Cheung & Ferring & 1 & University of Alberta & S van Zanten \\
Jennifer O'Hara & Janssen-Ortho & 2 & University of Calgary & A Buret \\
Rithwik Ramachandran & Janssen-Ortho & 2 & University of Calgary & M Hollenberg \\
Camila Dale & Schering & 2 & University of Calgary & N Vergnolle \\
\hline
\end{tabular}

CCFC Crohn's \& Colitis Foundation of Canada

Table 3

Canadian Association of Gastroenterology (CAG)-Crohn's \& Colitis Foundation of Canada (CCFC)-funded Summer Studentships (2007)

\begin{tabular}{|c|c|c|c|}
\hline Candidate & Sponsor & Institution & Supervisor \\
\hline Ausma Ahmed & CAG & University of Toronto & P Brubaker \\
\hline Anderson Hsu & CAG & University of British Columbia & T Kieffer \\
\hline Guan (Jane) Huang & CAG & University of Toronto & P Brubaker \\
\hline Kelly McCowan & CAG & University of Calgary & D Butzner \\
\hline Anton Namolovan & CAG & University of Toronto & J Brumell \\
\hline Joanne Rybicka & CAG & University of Calgary & K Chadee \\
\hline Aaron Yuen & CAG & University of Western Ontario & C Creuzenet \\
\hline Alexander Chow & CCFC & University of Toronto & A Griffiths \\
\hline Christine Chow & CCFC & University of Toronto & A Griffiths \\
\hline Jacqueline Hayworth & CCFC & University of Western Ontario & C Creuzenet \\
\hline Nikolaus Jewell & CCFC & McMaster University & K Croitoru \\
\hline Garming Lai & CCFC & University of Toronto & M Silverberg \\
\hline Pearl Leung & CCFC & University of Calgary & K Chadee \\
\hline Rohan Parab & CCFC & University of Calgary & K Rioux \\
\hline Mryanda Sopel & CCFC & University of Calgary & A Stadnyk \\
\hline Kevin St. Arnaud & CCFC & University of Alberta & K Madsen \\
\hline Robert Vanner & CCFC & Queen's University & J MacLeod \\
\hline Carolyn Wong & CCFC & University of Calgary & K Chadee \\
\hline
\end{tabular}

CAG-CIHR-Partnered Postdoctoral Operating Fellowship Program

The fellowship program is the cornerstone in the CAG research activities and its sustained success makes it a model for other societies. This year, 37 fellowship applications were received. With support from CIHR, the CCFC and CAG's industrial partners (see acknowledgements), 14 fellowships were funded (Table 2) - a 35\% success rate. Twelve of 30 applications from $\mathrm{PhD}$ scientists (40\%) and two of seven applications from MD scientists (29\%) were funded.

CAG Summer Studentships

It is critical that young investigators be supported at all levels of their training. Thus, in partnership with CCFC, 18 students received awards (salary plus a small operating budget; $\$ 6,000 /$ award) to work in laboratories of recent or established investigators whose interests cover many facets of gut function (Table 3). Twenty-three applications were reviewed, giving approximately a $78 \%$ success rate in this year's competition.

Resident Research Program

This initiative, launched in 2003/2004, provides gastroenterology residents with $\$ 5,000$ to fund research projects that can run throughout an academic year. With support this year from Axcan, Procter \& Gamble and Novartis, seven candidates applied for and were granted the award (Table 4). 
Table 4

Canadian Association of Gastroenterology-funded Residents Research Award (2007)

\begin{tabular}{lcll}
\hline Candidate & Sponsor & Institution & Supervisor \\
\hline Michael Bernstein & Axcan & University of Toronto & J Irvine \\
Dana Moffat & Axcan & University of Manitoba & C Bernstein \\
Charlie Shihn Wang & Axcan & University of Toronto & E Yoshida/J Tinmouth \\
Alexander Ford & Novartis & McMaster University & P Moayyedi \\
Adriana Lazarescu & Novartis & Queen's University & W Paterson \\
Jonathan Wyse & Novartis & McGill University & A Barkun \\
Samuel Asfaha & Procter \& Gamble & University of Calgary & N Vergnolle
\end{tabular}

\section{Congratulations}

Congratulations to all the successful awardees. We look forward to your contributions and your continued participation in Canadian GI research and CAG activities. And again, many thanks to CIHR and the CAG partners - the 18 summer studentships, seven resident research awards, 14 fellowships, and five grants add up to a research dollar commitment in 2007 of $\$ 2,543,000$. Simply outstanding!

Canadian Digestive Diseases Week 2007 and Third Annual Canadian Association for the Study of the Liver Winter Meeting

In addition to reviewing research applications, the other main role of the research committee is to review abstracts submitted to Canadian Digestive Diseases Week (CDDW), which showcases the best of Canadian GI research. A total of 279 abstracts were accepted to the core CDDW/Canadian Association for the Study of the Liver (CASL) Winter Meeting scientific program; 42 as CAG or CASL oral presentations and the remainder in one of two poster sessions.

The following are the 2007 recipients of CAG awards:

- Dr Andre Buret (University of Calgary) - Research Excellence Award;

- Dr Bruce Vallance (University of British Columbia) - Young Investigator Award;

- Dr John Wallace (University of Calgary) - Visiting Professor;

- Dr Alan Thomson (University of Alberta) - Education Excellence Award;

- Dr Jamie Gregor (University of Western Ontario) - Young Educator Award; and

- Professor John Dent (University of Adelaide) - The RD McKenna Memorial Lecturer.

This year's student research prizes were awarded, based on the quality of submitted CDDW abstracts, to: $\mathrm{Mr} \mathrm{A}$ Flynn, University of Calgary, Mr M Lejeune, University of Calgary (CAG sponsored), Ms N Godwin, University of
Ottawa and Mr T Murdoch, University of Alberta (CCFC sponsored).

The Implementation Committee has already convened and plans are underway for CDDW 2008.

\section{Research Topics VI Meeting}

Held in October 2006 at Kingbridge Centre, King City, Ontario, 37 students and trainees, both basic science and clinical, were invited to give oral presentations and six established or junior faculty served as mentors (see Can J Gastroenterol 2007;21:125-126). This really is a trainee meeting, with the students and fellows chairing the sessions and dominating the discussion periods. Feedback from the trainees was once again overwhelmingly positive - clearly this is a beneficial and much enjoyed event. Financial support was provided by AstraZeneca Canada Inc and the scientific program was reviewed by Drs G Greenberg (University of Toronto), K Croitoru (McMaster University) and K Chadee, with the CAG National Office coordinating the abstract submission, meeting management and event.

Research Topics VII is set for October 12 to 14, 2007 and abstracts are now being accepted online at <www.cagacg.org >. Any area of GI research is eligible (independent of the broad topics identified on the abstract form) and abstracts are selected for presentation based on review of scientific merit.

It has once again been an excellent year for Canadian GI research and everyone involved deserves congratulations. Should CAG members have questions relating to the work of the Research Committee or proposals on how to expand or promote our activities please contact me or any member of the committee.

ACKNOWLEDGEMENTS: Funding for the 2007 year from the following partners is gratefully acknowledged: Canadian Institutes of Health Research, Abbott, AstraZeneca Canada Inc, Axcan Pharma Inc, Crohn's and Colitis Foundation of Canada, Ferring Pharmaceuticals, Janssen-Ortho Inc, Novartis Pharmaceuticals Canada Inc, Nycomed, Olympus Canada Inc, Procter \& Gamble Pharmaceuticals and Schering Canada Inc. 


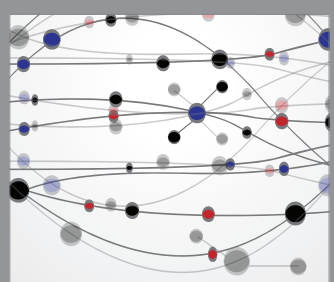

The Scientific World Journal
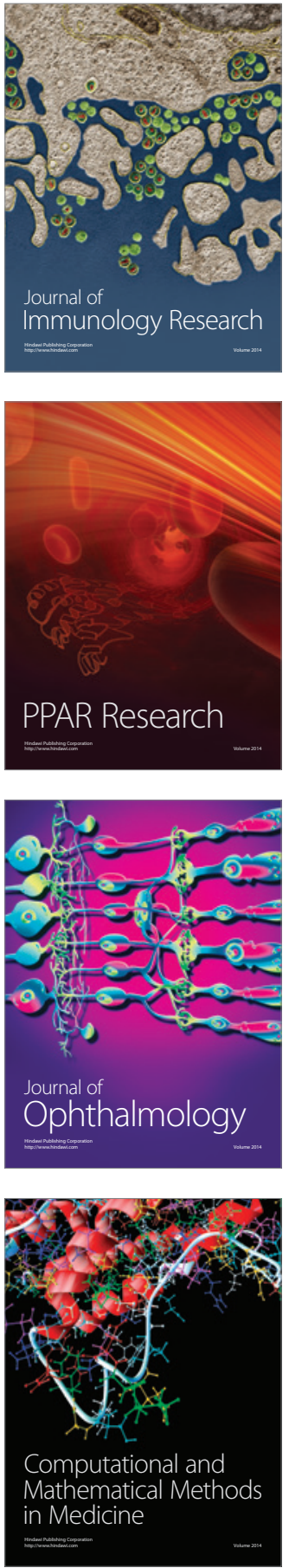

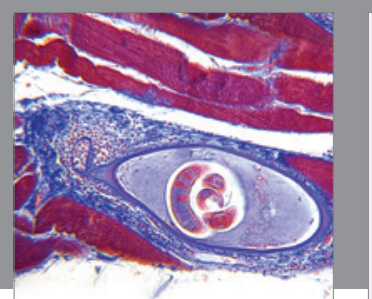

Gastroenterology Research and Practice

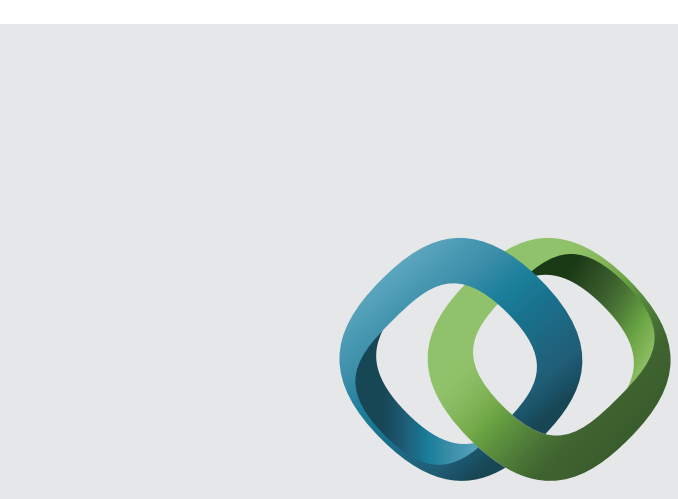

\section{Hindawi}

Submit your manuscripts at

http://www.hindawi.com
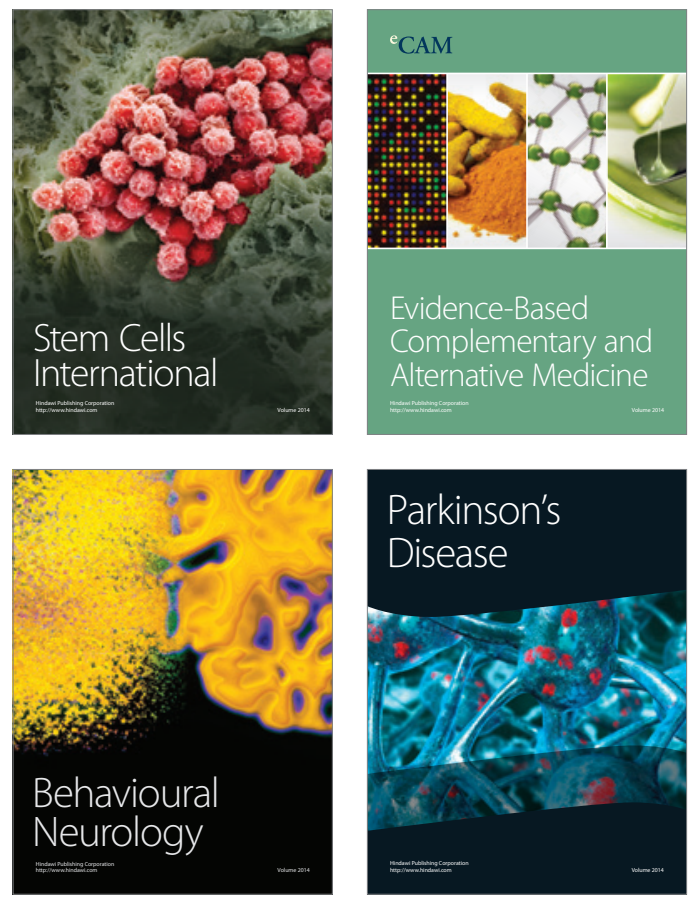
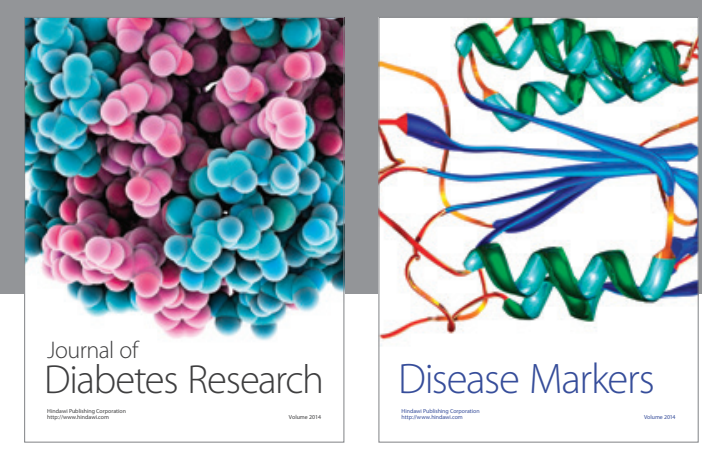

Disease Markers
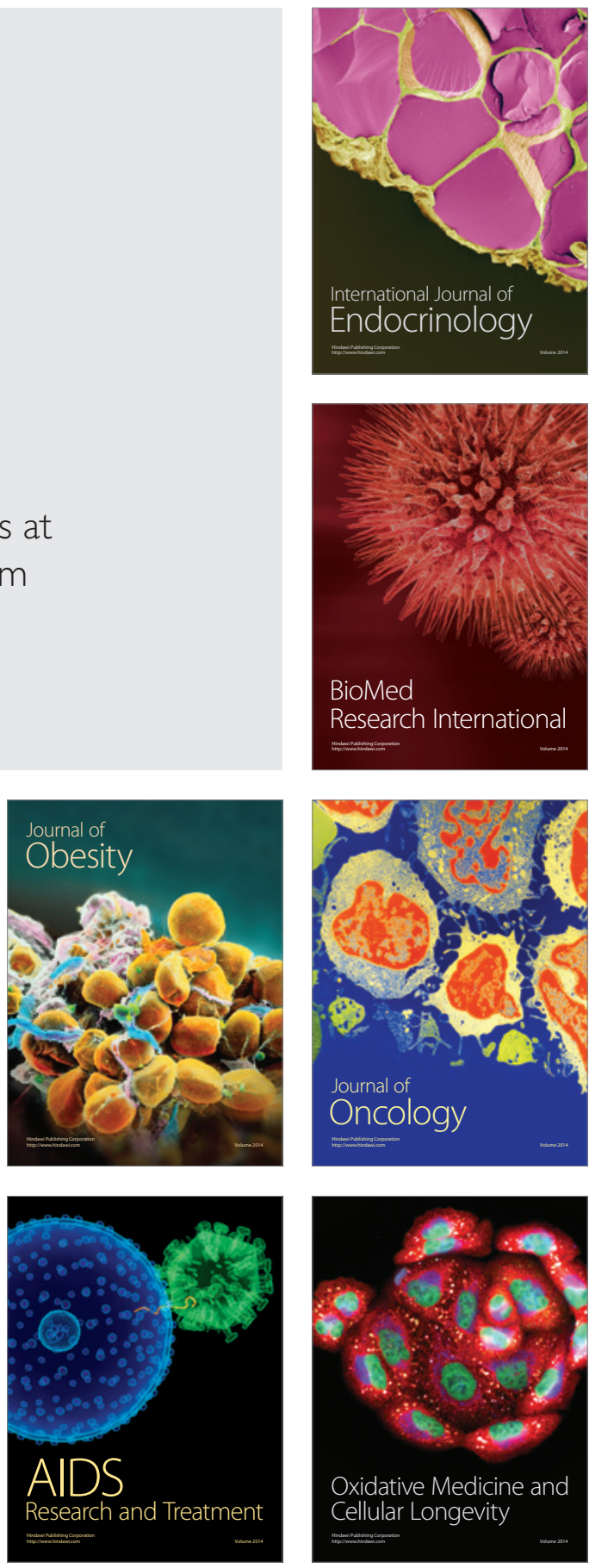